\title{
O Outro Mundo dos celtas atlânticos e a mítica Brasil, ilha dos afortunados: primeiras abordagens
}

\author{
Ana Donnard \\ ILEEL - UFU/ FAPEMIG \\ anadonnard@ileel.ufu.br
}

RÉSUMÉ: À l'Ouest de l'Europe, dans la mer celtique et plus loin dans l'Atlantique, une géographie celte de l'Autre Monde peut être identifiée. Dans cette géographie l'île Brasil est un élément de mythologie celte passé à un folklore chrétien. Nous essayons de comprendre comment le mythe d'une île de la mythologie celte, en l'occurrence l'île Brasil, ait passé, probablement, d'une littérature orale ou écrite perdue à la littérature et à la cartographie médiévales. Pour cela il nous faut travailler dans le champ difficile de l'hagiographie celtique et celto-latine en ayant aussi comme matériau d'analyse et comparaison les récits mythologiques, plus particulièrement les immarama: narratives de circunavegation des héros celtiques.

MOTS-CLÉS: celtologie; mythologie celtique; l'Autre Monde; île Brasil; narratives de voyage.

A primeira pergunta que podemos pressentir de imediato quando sugerimos a origem céltica do nome Brasil é aquela referente à velha assertiva, tantas vezes repetida nas nossas escolas: Brasil vem de brasa em analogia com a cor vermelha da madeira nativa? E a resposta sempre foi: o nome Brasil deve sua origem ao intenso comércio do pau-Brasil, madeira de cor avermelhada designada pelo vocábulo português brasa que, por sua vez, passa a ser associado definitivamente ao nome da colônia portuguesa nos documentos e crônicas, sendo posterior à denominação primeira de Terra de Santa Cruz. Sabe-se, de longa data, que esta não é a boa explicação. Desde o século treze os mapas da cartografia medieval assinalavam a ilha mítica Brasil da mitologia celta ao extremo oeste da Irlanda. Ao longo dos séculos, a ilha foi sendo deslocada nos mapas até chegar à costa do que conhecemos hoje como América do Sul.

Várias foram as designações para a madeira de cor avermelhada utilizada pelos europeus como tinta para tecidos e outras utilidades: verzino pelos venezianos, bois de pernanbouc pelos franceses, arboles de tinturería pelos espanhóis, araboutan pelo incrível cronista Jean de Léry, ibirapitanga pelos indígenas, Presilholtz (madeira do Brasil) pelos alemães em 1514, verniz pelos portugueses e brisilicum para designar o pau do Brasil por Duarte Pacheco em circa 1505. A confusão entre o termo celta e a designação do pau-Brasil teve inicio a partir de um planisfério conhecido como Kunstmann IV, que toma um termo pelo outro, anunciando que o nome brasil derivava da abundância de "tinta brasil" encontrada sobre seu solo. Posteriormente, o erro foi sedimentado pelo cronista português frei Vicente do Salvador, ao se insurgir contra a 
má fé do demônio. Segundo frei Vicente, teria sido o diabo quem inspirou a mudança do nome de Terra de Santa Cruz para Brasil, pois que a designação anterior referia-se à madeira em que foi crucificado o santíssimo Jesus Cristo e esta outra nada mais era do que uma madeira que servia ao tão mundano destino da fabricação de vestidos!

Pode-se perceber, por esta declaração, que o franciscano em questão não era um grande erudito, bem ao contrário, visto que a tradição cartográfica portuguesa já assinalava, desde época bem mais remota, a ilha mítica Brasil no oeste Atlântico. A primeira pista a seguir não pode ser outra: as hagiografias célticas e celto-latinas da Irlanda e da Bretanha armoricana. A razão é o fato de que, durante séculos, estas tradições hagiográficas retransmitiram o mito do paraíso terreal através das ilhas do mar céltico e do oceano Atlântico. Assim, tal qual Duarte Pacheco que, com sua etimologia selvagem havia dado à madeira ibirapitanga dos indígenas o nome de brisilicum, frei Vicente também contribuía, à sua maneira, para obscurecer a origem mítica do nome Brasil. De erros em enganos foi-se sedimentando a assimilação do vocábulo brasa ao nome Brasil, perdendo seu significado primitivo como metonimia do Outro Mundo dos celtas atlânticos.

O equívoco ou a dificuldade em se entender esta viagem do nome brasil entre mitologia, linguística histórica e cartografia medieval chega até o século $\mathrm{XX}$ com Capistrano de Abreu, que afirmava categoricamente que a ilha dos celtas não tinha nada a ver com o produto oriental descrito pelos venezianos com o nome de verzino. E ele estava certo, mas não inteiramente, pois descartava por completo a noção mitológica que havia prevalecido antes, oriunda da cartografia e da influente literatura arturiana de fundo céltico que prevaleceu na Europa durante tantos séculos. ${ }^{1}$

Obviamente, o interesse econômico pelas terras distantes não foi o único motivo das navegações em direção ao desconhecido. Este é o interesse que permeia o mundo factual, concreto e claramente verificável. Mas há também as navegações de peregrinação, onde o espírito é transportado pelos desejos e angústias de homens que se permitem levar em alto mar pelas correntes marítimas. A navegação pelos mares se igualava à peregrinação no deserto. Esta foi uma das principais aventuras de um cristianismo céltico que influenciou de forma significativa a literatura medieval, num comércio entre gênero hagiográfico e literatura pré-cristã de fundo druídico. A

\footnotetext{
${ }^{1}$ Toda essa matéria está apresentada e muito bem documentada na obra de Weckman, L. La herencia medieval del Brasil. México: Fondo de Cultura Económica: 1993, da qual apresentamos nestes três parágrafos apenas um brevíssimo resumo.
} 
primordial motivação em busca por riquezas é uma explicação simplista de um quadro muito complexo. Frequentemente, a historiografia literária é negligenciada em relação aos contextos sociais e culturais engendrados pela busca de novas terras atlânticas. É preciso entender, por exemplo, o fenômeno avassalador do mito arturiano e do ciclo literário bretão que se desencadeou em toda a Europa a partir do final do século XII, depois de Godofredo de Monmouth e de sua obra fundadora Historia regum Britanniae.

Não seria difícil avaliar o impacto, para o homem medieval, da ideia de encontrar-se com seres que habitavam estas ilhas míticas da cartografia, quando nós mesmos hoje transportamos nossa imaginação em direção ao espaço sideral através da navegação interestelar e da pergunta incontornável sobre a possibilidade de encontramos habitantes de outros mundos completamente desconhecidos. Não há limites para a imaginação que opera entre realidades vividas e mitologias variadas, que alimenta sonhos de enriquecimento e ficções literárias através de um vasto campo de indagações. A literatura hagiográfica é um gênero onde se pôde fazer valer as imagens emprestadas de mitologias degradadas, estratégia de criação literária para a construção de um cristianismo mundial, expandido e em expansão constante em direção a outros mundos. O impressionante arquivo da literatura hagiográfica pode ser investigado em relação com as obras profanas medievais, que representam um ciclo enorme de uma literatura que foi parte integrante e importante de uma nova era cultural após a Antiguidade. Durante séculos, o enorme canevas da literatura arturiana fez passear pela Europa uma mitologia celta que se desdobrou em vários motivos folclóricos pelas várias literaturas venaculares que se constituiam durante o longo periodo medieval.

Quanto à influência da cultura céltica, da qual o mito arturiano é apenas o mais conhecido, é necessário avaliar a importância da igreja céltica e de seu papel enquanto escola de saber e de tradição literária. A dimensão desta literatura medieval céltica pode ser avaliada através da intensa produção de textos nos centros monacais irlandeses e bretões, de onde partiram milhares de manuscritos. Estes manuscritos, quer tenham sido encomendados ou pilhados, fizeram circular tradições orais e escritas e, obviamente, um conjunto de mitologia que representa hoje um dos principais patrimônios desses países de língua céltica. ${ }^{2}$

\footnotetext{
${ }^{2}$ Os paises célticos são: Bretanha armoricana (França), Irlanda, Inglaterra e Escócia. A Galícia e Portugal, por terem perdido suas línguas celtas para o latim, não são considerados países célticos, mas o Lusitano tem sido visto pela linguística histórica como sendo possivelmente o testemunho mais antigo da aventura celto-Atlântica e, na Galicia, encontramos inúmeros sítios arqueológicos que comprovam a antiquidade de seus produtos e a unidade cultural destes territórios do oeste europeu. Cf. Donnard, A. Celtas e Gregos:
} 


\section{nuntius antiquus}

A repartição das relíquias de um santo céltico e sua recepção em outros territórios nem sempre era acompanhada de sua Vita, mas a transmissão destes textos era frequente e como já se sabe a hagiografia, enquanto gênero literário, possibilitou a transmissão de vários conteúdos provenientes de um fundo de memória celta précristão. Na verdade, o que aconteceu e que se tornou tabu, permanencendo de certa forma assim até os dias de hoje, é admitir o fato de que a hagiografia celto-latina ou céltica tenha preservado, e de forma surpreendente, o material mitológico de fundo druídico, portanto oral. Paralelamente à produção hagiográfica, a mise en écriture das narrativas mitológicas pelos monges célticos tornou possível um estudo comparativo de grande importância entre Celtas e Gregos, revelando várias facetas de um patrimônio europeu de grandes proporções linguísticas e culturais. ${ }^{3}$

Em suma: a hagiografia e as narrativas mitológicas preservadas pelos monges célticos foram responsáveis por uma parte significativa de motivos e imagens da literatura medieval, dentre as quais a famosa ilha de Avalon e a cidade encantada de Camelot, destino de Arthur após a batalha de Camlam. Nesse caso, trata-se da matéria arturiana e de uma produção literária secular. No que se refere à literatura hagiográfica, temos a matéria brendaniana. Acessando essa matéria, podemos entender o fenômeno da ilha Brasil nas cartografias medievais, ou seja, trata-se de examinar a influência da Nauigatio Sancti Brendani (Navegação de São Brandão) na produção hagiográfica espanhola e portuguesa, precedendo o período das navegações marítimas no Atlântico e dos "descobrimentos" das terras americanas. ${ }^{4}$

De imediato podemos assinalar duas especificidades na matéria brendaniana: primeiro a inserção da narrativa de navegação dentro do contexto hagiográfico. Em segundo lugar, a premissa de uma terra prometida a se descobrir antes dos fins dos tempos. O Outro Mundo se revela na matéria brendaniana, como passível de reconhecimento pela alma cristã que o reconhece como paraíso terrestre e ao qual se pode chegar através de uma peregrinação pelas águas de um mar desconhecido. E, quanto mais desconhecido, melhor para a alma cristã peregrina. Esta perspectiva vai de encontro à teoria de que os Celtas, conhecendo a esfericidade do globo terrestre,

ampliando territórios culturais (artigo acessado em 10 de junho de 2009 e disponível em: http://www.historiaehistoria.com.br/materia.cfm?tb=arqueologia\&id=23\#_ftn1).

${ }^{3}$ Cf. Sergent, B. Celtes et Grecs I. Le livre des héros. Paris: Payot, 1999.

${ }^{4}$ Cf. Selmer, C. Nauigatio Sancti Brendani abbatis from early Latin manuscripts. Dublin: Four Courts Press, 1989. 
acreditavam que ir para o oeste máximo seria encontrar o oriente, ou a Jerusalém celeste, o paraíso dos cristãos. ${ }^{5}$

Henrich Zimmer, um dos mais importantes celtólogos do final do século XIX, propôs uma influência substancial da literatura clássica na composição destas narrativas, nesse caso, a Odisseia e a Eneida, sobrepostas a um canevas hagiográfico executado com liberdades pouco habituais. Esta proposta foi sendo descartada, na medida em que o corpus das literaturas célticas, resultantes de estudos filológicos que evoluíram a partir de então, revelaram uma propriedade de conjunto impossível de ser construído apenas sob a influência de tradições estrangeiras. ${ }^{6}$

A situação da Irlanda como centro de escolas de saber na Alta Idade Média oferecia certamente a possibilidade de um comércio efetivo entre as tradições célticas e clássicas, e que foi efetuado com proveitoso talento em vários outros setores da produção literária céltica, como na Bretanha armoricana e na Inglaterra. Mas o material céltico, e, particularmente, o irlandês se sobrepõem consideravelmente, revelando um "Outro Mundo", é claro, com vários paralelos clássicos, mas advindos de uma outra esfera de "comércio mitológico", anterior ao momento medieval das hagiografias e das composições nos monastérios do oeste europeu. Este extenso painel mítico-literário précristão se constituiu em tempos mais remotos, provavelmente a partir de um estoque mitológico de que ambos gregos e celtas frutificaram suas literaturas. ${ }^{7}$

Antes da Navigatio Sancti Brendani, um outro gênero na literatura irlandesa apontava para uma tradição de literatura de viagens, que não era simplesmente uma influência da Odisseia ou da Eneida, como já assinalamos, mas tinha sua origem em outra vertente, a qual se pode considerar como de fundo puramente celta e que foi, na verdade, a matéria através da qual a Nauigatio redesenhou sua forma alternativa de narrativa hagiográfica. As narrativas de viagens chamadas de immrama (singular imram) são relatos de circunavegações de heróis irlandeses e constituem um conjunto significativo para o exame de um universo céltico em que o Outro Mundo se revela ao herói através de manifestações intermediadas quase sempre pelas águas brumosas e por ilhas que surgem e desaparecem. Um dos elementos constitutivos "deste Outro Mundo

\footnotetext{
5 Cf. Beauvois, E. La découverte du nouveau monde par les Irlandais et les premières traces du christianisme avant l'an 1000. Nancy: Crépin-Leblond, 1875.

${ }^{6}$ Cf. Zimmer, H. Keltische Beiträge II. Brendans Meerfahrt. Zeitschrift für Deutsches Alterthum und Literatur Leipzig: Weidmannsche Buchhandlung, vol. XXXIII, p. 129-220, 1889.

7 Cf. Thrall, F. W. Vergil's Aeneid and the Irish "immrama”. Zimmer's theory. Modern philology, Berkely : University of California Publications, vol. XV, n. 8, p. 449-474, 1917.
} 
céltico é a suspensão do tempo, quando um dia tem a duração de um ano. O herói e seus companheiros transitam nestas ilhas até o retorno à terra de origem depois de uma longa peregrinação e de muitos anos em exílio maravilhoso.

As narrativas célticas habitualmente comparadas à matéria brendaniana são: Imram Brain maic Febail ("Viagem de Bran filho de Febail") Imram Curaig Maelduin ("Viagem do barco de Maeldui"), Imram Curaig hua Corra ("Viagem do barco de Hui Corra"), Imram Brendan ("Viagem de Brendan"), Imram Snedgusa ocus mac Riagla ("Viagem de Snedgus e Mac Riagla"). Para o quadro de uma análise comparativa da Navigatio Brendani, acrescenta-se também a Echtra Clereth Choluim Cille ("Aventuras dos clérigos de Columb Cille"), sendo esta última narrativa parte do estoque literário do cristianismo céltico, enquanto as anteriores se inserem na tradição pré-cristã. Essas narrativas foram coletadas e transcritas entre os séculos VII e XI e são, portanto, anteriores à tradição hagiográfica brendaniana.

A Nauigatio é um texto independente das duas outras vidas latinas de São Brandão, conhecidas como Vitae primae Sancti Brendani e cujos manuscritos são datados entre os séculos XIV e XV, mas a composição e a língua atestando uma data mais antiga, entre meados dos séculos XI e XII. Temos, nestes textos, o tema da peregrinação terrestre do santo. A Vita secunda Brendani, cujos manuscritos são datados do século XVIII, trata também de peregrinação, mas, neste caso, de uma peregrinação marítima. A Betha Brenainn ("Vida de Brandão") é um texto hagiográfico em irlandês medieval de composição do final do século XI, cujo manuscrito é datado do século XV, conhecido como o Book of Lismore. ${ }^{8}$ E o manuscrito de Lisboa da Navegação, em latim, parece ser uma recensão das diferentes aventuras do santo, comprovando o sucesso da tradição brendaniana em Portugal. ${ }^{9}$

O texto fundador da tradição brendaniana seria o manuscrito da Nauigatio de Alençon, proveniente da Abadia de Santo Evroult na Normandia e atualmente em ruínas. ${ }^{10}$ A datação não resulta unânime entre os filólogos, estando dentro de uma margem entre os séculos XI e XII. ${ }^{11}$ A Navegação insere-se na tradição hagiográfica,

\footnotetext{
${ }^{8}$ Cf. Stokes, W. Lives of saints from the Book of Lismore. Texts and translations. Oxford: University Press, 1890.

${ }^{9}$ Cf. Selmer, C. The Lisbon Ms. of the "Nauigatio". Traditio. New York, vol. XIII, p. 313-344, 1957.

${ }^{10} \mathrm{O}$ manuscrito faz parte do acervo da Biblioteca municipal de Alençon, codex 14, fólio $1 \mathrm{r}$ a II v.

${ }^{11}$ Sobre a controvérsia das datas de composição da Nauigatio, consultar os seguintes estudos: Selmer, C. The manuscripts of the "Nauigatio". In :____ Nauigatio sancti Brendani abbatis from early Latin manuscripts. Notre Dame: University of Notre Dame Press, 1959, p. 26-37; Dumville, D. Two approaches to the dating of the "Nauigatio Sancti Brendani". Studi medievali. Torino, vol. XXIX, n. 1, p.
} 
mas ao mesmo tempo parece ser muito mais uma obra de criação literária de estilo alegórico do que uma obra de edificação moral. Sua influência foi definitiva tanto para os geógrafos quanto para a formação da educação cristã e para o estudo do latim, como também para a formação da literatura vernácula céltica, sendo considerada por vários estudiosos como um dos mais importantes elementos na constituição da matéria do Graal. ${ }^{12}$ A importância da Nauigatio reside no fato de que ela surge antes dos textos hagiográficos propriamente ditos relacionados ao santo, confirmando uma posição intermediária entre o fundo de memória céltica e a adaptação clerical dos elementos précristãos.

Antes de partir para a conquista de terras e mares, Cristóvão Colombo passou anos como cartógrafo em Lisboa. Seu filho Fernando dá testemunho de que o navegante era conhecedor da Nauigatio Brendanici, e isso explicaria a representação da ilha de Borondon nos mapas, mas não explicaria a ilha Brasil. O fato é que se a disseminação de uma mitologia brendaniana sobre as ilhas afortunadas do oeste atlântico se deveu a um sucesso representativo da Nauigatio entre os ibéricos, a frequente aparição da ilha Brasil na cartografia medieval não pode ser explicada por uma influencia direta da matéria brendaniana. Não há nos textos hagiográficos e tampouco na Nauigatio, menção à ilha Brasil. O que existiu, certamente, foi a disseminação da ideia de que as ilhas das narrativas mitológicas poderiam esconder algum fundo de realidade factual com a qual os navegantes portugueses poderiam contar em suas expedições. Mas como exatamente a ilha Brasil surge nos mapas e permanece neles como uma tradição celto-portuguesa é uma matéria que merece uma apurada investigação, sem dizer que a documentação para esta pesquisa se encontra toda ela em bibliotecas da Europa, precisamente, em Portugal, na Irlanda, na França, na Inglaterra e na Espanha (Galícia), sem esquecer obviamente a Biblioteca do Vaticano. Trata-se, portanto, de uma investigação de alto custo financeiro, razão pela qual não foi ainda possível avançar a pesquisa preliminar.

Como explicar o nome Brasil na cartografia medieval desde o século XII, sendo produtiva até meados do século XVII? Qual a origem deste nome? Qual o seu significado? Diante de uma simples análise quantitativa de sua representação na cartografia medieval não podemos evitar a impressão de que o nome Brasil representava

87-102, 1988; Esposito, M. An apocryphal "Book of Enoch and Elias" as a possible source of the "Nauigatio Brendani”. Celtica. Dublin, vol. V, p. 192-206, 1960.

${ }^{12}$ Cf. Loomis, R. S. Irish "Immrama" in the "Conte del Graal". Romania. Paris, vol. LIX, p. 548-557, 1933. 
alguma coisa muito significativa para geógrafos e navegantes europeus, mas, sobretudo, para os portugueses.

Obviamente, podemos traçar um caminho em direção a algumas indagações ou tentar encontrar elementos que expliquem de forma consistente, ou senão, pelo menos de forma parcial, essa significativa presença de um elemento céltico recorrente na cartografia e que não encontra seu correspondente nas fontes escritas latinas e hagiográficas, tampouco na tradição brendaniana. Luis Weckmann apresenta em sua $L a$ herencia medieval del Brasil uma relação cartográfica e chama a atenção para o fato de que a ilha Brasil tenha continuado a ser assinalada pelos portugueses até 1500. Sabe-se que um marinheiro português chamado Antônio Leme havia contado ter visto ilhas "das tais como as que chamam de São Brandão e nelas viu muitas maravilhas". ${ }^{3}$

Se as razões pelas quais os Portugueses apaixonaram-se pela ideia de uma ilha no Atlântico chamada Brasil é uma matéria envolvida em brumosas hipóteses, a origem da palavra Brasil também tem sua dificuldade e precisa ser primeiramente entendida no seu registro mais imediato, que é o folclore irlandês.

A Irlanda possui um elenco numeroso de pequenas ilhas míticas, como satélites em torno da grande ilha que é a própria Irlanda. Cada ilha possui sua lenda específica, mas em quase todas as lendas a ilhas aparecem e desaparecem, deslocando-se, mais ao norte ou mais ao sul. Essa mobilidade e visibilidade intermitente é parte integrante do folclore irlandês e a ilha Brasil tornou-se a mais famosa dentre todas as ilhas-fantasma, ganhando sua internacionalização desde a época medieval, mas ficando todas as outras ilhas da Irlanda restritas ao folclore nacional. Existem diferentes grafias: Ui Breasail, Hy Brazil, Breasal, e para uma etimologia temos várias hipóteses. O vocábulo gaélico bress poderia indicar alguma pista, mas limitada ainda. Seu significado é "nobre" ou "afortunado". Breasal por sua vez seria o nome de um herói celta que também é obscuro e que teria dado seu nome à ilha por ali ter sido sepultado em tempos imemoriais. Sabemos pela literatura arturiana que os heróis guerreiros eram enterrados numa ilha mágica, assim como Arthur em Avalon. Contudo, as lendas relativas à famosa ilha Brasil são inúmeras, bem como seus diversos epítetos, como, por exemplo: a ilha dos viventes, ilha da verdade, da alegria, da mulher encantada, das maçãs, um paraíso maisque-distante, para citar os mais conhecidos. Na hagiografia, esses elementos permaneceram, mas por força da escatologia cristã, as ilhas do Outro Mundo da

${ }^{13}$ Cf. Iglesia, R. (org.). Vida del almirante. México: Fondo de Cultura Económica, 1947. 
mitologia céltica foram assimiladas à terra da promissão. ${ }^{14}$

Entre mitologia degradada em folclore e a pura especulação fantasiosa pouco se pode dizer de substancial sobre o nome Brasil. Mas, pela frequência com que aparece na cartografia medieval e pela configuração com que ela se institucionalizou no folclore moderno, só se pode concluir que a ilha Brasil tenha sido um elemento importante de uma mitologia antiga e, como tantos outros mitemas do mundo céltico, tenha ficado perdida num passado impossível de ser reconstituído em toda sua completude. Restamnos, infelizmente, apenas os fragmentos de uma mitologia que aponta claramente para sua identificação através de um conjunto de narrativas de viagem ao Outro Mundo da literatura gaélica medieval: os immrama.

A pergunta que se pode formular até aqui é: a fama da ilha Brasil entre os portugueses seria devida apenas a uma influência mitológica transmitida pela cartografia medieval, sem que o fundo original se tenha sedimentado a ponto de poder ser identificado, ou haveria um comércio maior entre Portugal, Irlanda e Bretanha além do que se espera através da tão comum migração de monges irlandeses, como é frequentemente assinalado? Se o fundo mitológico se explica apenas pela influência da Nauigatio, que por sua vez é devedora das immrama, por que a ilha Brasil escapa a uma descrição nos textos hagiográficos? Se Brandão deu nome a uma ilha, seria Brasil um personagem desconhecido que se perdeu nas brumas de uma tradição oral pré-cristã? Se tal é a possibilidade, estaríamos tentando acessar inutilmente a mitologia da ilha Brasil através da transmissão de textos hagiográficos, pois que, nesse caso, tratar-se-ia de uma literatura perdida? Teria a Nauigatio Sancti Brendani sido a única tradição hagiográfica responsável pela disseminação de uma mitologia das ilhas Atlânticas ou outras influências lusitanas teriam alimentado" o caldeirão das hagiografias medievais do oeste insular e peninsular? ${ }^{15}$

\footnotetext{
${ }^{14}$ Sobre a ilha Brasil no folclore irlandês, duas referências são fundamentais: Westropp, T. J. Brasil and the legendary islands of the north atlantic. Their history and fable. A contribution to the "Atlantis" problem. Proceedings ot the royal Irish academy. Dublin, vol. 30, n. 8, 1912; Campbell, J. F. (org.). Popular tales of the west Highlands, orally collected with a translation by J. F. Campbell. Edinburgh: Gardner Editors, 1890. Tomo IV, p. 161, 163, 265.

${ }^{15}$ Sobre os espaços peninsulares e insulares do mundo céltico, lembramos que a Bretanha armoricana é a peninsula francesa que na Antiguidade era denominada Armórica, e onde se fala até hoje a língua bretã. As grandes ilhas são a Inglaterra, chamada de Britannia pelos romanos e que denominamos Bretanha insular em relação à Bretanha peninsular ou armoricana. A Irlanda e a Escócia faziam parte das ilhas mais distantes, que eram denominadas em conjunto pelos gregos como as Hespérides. A península ibérica corresponderia, no caso das culturas célticas propriamente ditas, ao norte de Portugal e à Galicia, se nos atemos ao mundo cristianizado da Antiguidade tardia e que nos interessa para o caso das hagiografias celto-latinas. Note-se que todo este território no extremo oeste da Europa é permeado de ilhas e penínsulas desde o norte da Escócia até a costa da Galícia. Sobre as relações culturais e comerciais
} 
Estas são perguntas que demandam uma incursão significativa na crítica textual das hagiografias ibéricas e celto-latinas, o que não se pode empreender sem o acesso a uma documentação que não está facilmente acessível, nem mesmo nas bibliotecas das universidades europeias, como já assinalamos. Uma hagio-historiografia comparativa aliada a uma crítica textual para levantamento das formas literárias, motivos, empréstimos e influências de mitologias disseminadas nas tradições manuscritas dos centros de produção na Espanha, Portugal, Bretanha e Irlanda não pode ser empreendida por um único pesquisador isolado em suas angústias documentais. Seria necessário uma equipe que pudesse catalogar, analisar e discutir as inúmeras contaminações, transmissões e tradições específicas a cada universo particular e um financiamento para a obtenção dos documentos, bem como para estágios de supervisão de especialistas europeus. É curioso notar como o nome do nosso país, apesar de tão interessante e significativo do ponto de vista histórico-literário, não despertou a curiosidade ou o empenho de especialistas brasileiros. As razões me escapam, e posso apenas imaginar que a falta de conhecimento do universo cultural céltico em nossas universidades tenha contribuído para a falta de interesse em aprofundar as questões relativas ao nome do nosso país, "Brasil".

Nosso projeto de pesquisa pode ser empreendido se pudermos construir, a partir de um estudo preliminar, a hipótese de que a ilha mítica Brasil, reconhecidamente de proveniência irlandesa, deve seu sucesso entre os portugueses não apenas a uma tradição da cartografia medieval, que por sua vez é resultante do sucesso da Nauigatio, mas também às influências bretãs na península ibérica, especificamente na Galícia e em Portugal. Esse fenômeno literário pode ser avaliado através das diferentes etapas de constituição das dioceses e do trânsito não só de homens da Igreja em formação na Antiguidade tardia, mas também de tradições literárias ou tradições orais célticas retransmitidas através do gênero hagiográfico.

Podemos avançar ainda mais na construção de uma hipótese de trabalho se considerarmos a possibilidade de que uma tradição de narrativas de navegação ao estilo das immrama irlandesas, mas provenientes de um fundo lusitano, foram adaptadas ao modelo hagiográfico sem que tenha havido necessariamente apenas uma influência brendaniana, mas conjugada a ela. A Nauigatio, por ter conhecido um sucesso muito

mantidas desde a Antiguidade por estes povos atlânticos do mundo céltico, cf. obra do arqueólogo inglês Barry Cunliffe (Facing the Ocean. The Atlantic and its peoples 8000 B.C.-A.D. 1500. Oxford: University Press, 2001). 
grande, acabou por se tornar o único referencial para explicar os contos de navegação, obscurecendo outras possíveis tradições orais ou escritas de fundo lusitano. A Vida de Sancto Amaro e suas singularidades poderiam sugerir, então, outros caminhos de investigação.

Há que se distinguir duas vertentes na matéria brendaniana: a da Nauigatio propriamente dita e as versões das Vita Prima e Vita Secunda. Examinando a historiografia literária, constatou-se que o núcleo fundador da Nauigatio teve sua origem na Vita Sancti Malo, de origem armoricana, que, por sua vez, está relacionada à Vita Sancti Columbae. ${ }^{16}$ Não caberia aqui oferecer um resumo da intricada rede de transmissões e datações das hagiografias célticas e celto-latinas, e somos obrigados a remeter o leitor às referências bibliográficas. Mas, se a Nauigatio teve sua gênese ou seu núcleo na Vita Santi Malo, não é impossível que a Vita Sancti Amari tenha tido uma influencia bretã armoricana, mesmo que o texto amariano que nos chegou pelo manuscrito do mosteiro de Alcobaça seja muito tardio em relação à Vita Sancti Malo.

A Nauigatio possui várias traduções vernáculas, mas não foram encontradas as versões em língua portuguesa e espanhola, o que nos faz inferir que o conto amariano substituiu a matéria brendaniana na península ibérica. Erroneamente, o texto amariano é comentado como sendo uma "adaptação" da Nauigatio, sem a devida atenção para suas especificidades que o deixam muito longe de uma simples adaptação. Os dois textos hagiográficos amarianos em questão, em língua portuguesa e espanhola, fazem parte de outro estoque, de fundo céltico certamente, mas com elementos que merecem atenção quanto a uma tradição lusitana, no caso da vertente portuguesa.

O texto amariano em português apresenta apenas um códice, enquanto a tradição espanhola é mais produtiva. A Vida de Sancto Amaro existe, portanto, em duas versões: a portuguesa e a espanhola, e, segundo Klob, que editou o texto em 1901, nem a versão portuguesa nem, tampouco, a versão espanhola, podem ser a tradução uma da outra, mas ambas teriam sido geradas a partir de um texto comum perdido, provavelmente em língua latina. ${ }^{17}$ Como de Brasil, a ilha ou o personagem, também de Santo Amaro se ignora quase tudo. Mas o mais importante para uma análise da tradição amariana é constatar a sua popularidade. $\mathrm{O}$ tema amariano da busca pela ilha prometida tornou-se

\footnotetext{
${ }^{16}$ Cf. Anderson, A. O. Adomnán's life of Columba. London: Nelson, 1961; Cumming, J . G. (org.). The mission of the church and the propagation of the faith. Cambridge: University Press, 1970.

${ }^{17}$ Cf. Klob, O. A "Vida de Sancto Amaro", texte portugais du XVIème. siècle. Romania. Paris, vol. XXX, p. 504-518, 1901.
} 
material disseminado pela literatura de cordel até o século XIX. Durante quatro séculos, a lenda de Amaro foi reproduzida em Espanha e Portugal sem que sua matéria tenha sofrido alterações, o que leva a crer que a tradição amariana estava muito bem sedimentada na cultura portuguesa e espanhola, substituindo a Nauigatio e sobrepondose à fama brendaniana, tão disseminada no resto da Europa. Essa singularidade do conto amariano em relação à tradição brendaniana revela, portanto, um lugar atípico que merece maior investigação do ponto de vista de uma celticidade lusitana. As relações entre Bretanha armoricana, Galícia e Portugal desde a Antiguidade tardia podem explicar talvez essa vertente céltica que se fixou na literatura portuguesa e espanhola.

Os territórios galegos atestam a implantação de comunidades eclesiásticas bretãs desde o século VI e que perduraram até os séculos XI e XII. Os caminhos de Santiago de Compostela estão permeados por lendas e personagens bretões, o que explicaria a presença, ainda hoje, deste componente céltico no folclore galego e português, além de explicar, igualmente, a singular assimilação, na literatura medieval secular, das lendas do ciclo bretão na constituição da matéria da Bretanha galego-portuguesa. A fundação do arcebispado de Dume, na Galicia, unido em seguida ao arcebispado de Braga, no Minho, é a consequência de uma antiga migração bretã na península ibérica, cuja razão pode ser de ordem missionária, mas também decorrente das ondas migratórias que acompanharam as invasões saxônias na Bretanha insular, gerando na Bretanha peninsular ou armoricana um movimento em direção ao norte da península ibérica e que corresponderia ao momento em que a matéria arturiana se constituía na sua formação mais primitiva, visto que o período de implantação destas dioceses corresponde ao das migrações bretãs e da "atividade" de Arthur, isto é entre 555-578 d.C.

Acreditamos que um amplo material pode ser estudado em busca da elucidação de motivos, interpolações, contaminações e versões comuns na literatura hagiográfica e secular medieval das tradições galegas e portuguesas. Acreditamos ainda em que essa abordagem possa legitimar a inclusão deste patrimônio literário no âmbito das literaturas célticas. A intensa troca cultural e comercial entre os atlânticos desde tempos muito antigos admite uma expectativa que não pode ser outra senão a de se poder constatar um comércio literário comum. A ilha Brasil pode ter chegado até nós através das brumas de um "Outro Mundo" Atlântico, um paraíso terreal alimentado pelos sonhos das almas lusitanas. Se, através de seu nome, pudermos chegar a entrever uma 
literatura lusitana perdida, já será melhor do que deixarmos por brasa o que nunca foi braseiro.

\section{Referências}

ANDERSON, A. O. Adomnán's life of Columba. London: Nelson, 1961.

BARROSO, G. Brasil na lenda e na cartografia antiga. São Paulo: Cia. Editora Nacional, 1941.

BEAUVOIS, E. La découverte du nouveau monde par les Irlandais et les premières traces du christianisme avant l'an 1000. Nancy: Crépin-Leblond, 1875.

CAMPBELL, J. F. (org.). Popular tales of the west Highlands, orally collected with a translation by J. F. Campbell. Edinburgh: Gardner Editors, 1890.

CUMMING, J . G. (org.). The mission of the church and the propagation of the faith. Cambridge: University Press, 1970.

CUNLIFFE, B. Facing the Ocean. The Atlantic and its peoples 8000 B.C.-A.D. 1500. Oxford: University Press, 2001.

DAUNT, R. G. Tradição sobre a palavra Brazil. Revista do Instituto histórico e geográfico do Brasil. Rio de Janeiro, vol. 47, n. 1, 1884.

DAVID, P. Études historiques sur la Galice et le Portugal du VIe. au XIIe. siècle, Lisboa/ Paris: Portugália/ Les Belles Lettres, 1947.

DONNARD, A. Celtas e gregos: ampliando territórios culturais (artigo acessado em 10 de junho de 2009 e disponível para consulta em http://www.historiaehistoria.com.br/materia.cfm?tb=arqueologia\&id=23\#_ftn1).

DUMVILLE, D. Two approaches to the dating of the "Nauigatio Sancti Brendani". Studi medievali. Torino, vol. XXIX, n. 1, p. 87-102, 1988.

DUNN, J. The Brendan problem. Catholic historical review. Washington, vol. VI, p. 395-470, 1920-1921.

ESPOSITO, M. An apocryphal "Book of Enoch and Elias" as a possible source of the "Nauigatio Brendani”. Celtica. Dublin, vol. V, p. 192-206, 1960. 
IGLESIA, R. (org.). Vida del almirante. México: Fondo de Cultura Económica, 1947.

KLOB, O. A "Vida de Sancto Amaro", texte portugais du XVIème. siècle. Romania. Paris, vol. XXX, p. 504-518, 1901.

LOOMIS, R. S. Irish "Immrama" in the "Conte del Graal". Romania. Paris, vol. LIX, p. 548-557, 1933.

LOT, F. Mélanges d'histoire bretonne. Paris: Honoré Champion, 1907.

MERDRIGNAC, B. La désacralisation du mythe celtique de la navigation vers l'autre monde: l'apport de dossier hagiographique de Saint Malo. Ollodagos. Bruxelles, vol. V, p. 13-43, 1993.

PATCH, R. H. Some elements in mediaeval descriptions of the Otherworld. Proceedings of the modern langage association. New York, vol. XXXIII, n. 4, p. 601643, 1918.

ROMERO, F. A. Navegantes, monjes y piratas de las costas atlánticas en la Alta Edad Media. Santiago: Nautica, 1997.

- Crenzas e tradicións dos pescadores galegos, británicos e bretóns. A Coruña: Nautica, 1996.

. Galician legends about miraculous sea-voyages in stone boats: some Irish and Breton parallels. Études celtiques. Paris: Les Belles Lettres, vol. XXIX, p. 89-95, 1992.

SELMER, C. Nauigatio Sancti Brendani abbatis from early Latin manuscripts. Dublin: Four Courts Press, 1989.

$344,1957$.

. The Lisbon Ms. of the "Nauigatio". Traditio. New York, vol. XIII, p. 313-

. The manuscripts of the "Nauigatio". In : Nauigatio sancti Brendani Abbatis from early latin manuscripts. Notre Dame: University of Notre Dame Press, 1959, p. 26-37.

SERGENT, B. Celtes et grecques I. Le livre des héros. Paris: Payot, 1999.

STOKES, W. Lives of saints from the Book of Lismore. Texts and translations. Oxford: University Press, 1890. 
THRALL, F. W. Vergil's Aeneid and the Irish “immrama”. Zimmer's theory. Modern philology. Chicago, vol. XV, n. 8, p. 449-474, 1917.

VÁRIOS. Irlande et Bretagne: vingt siècles d'Histoire. Actes du Colloque de Rennes, 29-31 mars 1993. Rennes: Terre de Brumes Éditions, 1994.

VÁRIOS. La Bretagne, Le Brésil, le Portugal: échanges et rapports. Actes du cinquantenaire de la création en Bretagne de l'enseignement du portugais en co-édition des Universités de Nantes, de Haute-Bretagne et de Bretagne occidentale. Rennes: PUR, 1977.

WALKER, G. S. St. Columban: monk or missionary ? In: CUMING, G. J. (org.). The mission of the church and the propagation of the faith. Papers read at the seventh summer meeting and the eighth winter meeting of the ecclesiastical history society. Cambridge: University Press, 1970, p. 44-54.

WECKMAN, L. La herencia medieval del Brasil. México: Fondo de Cultura Económica: 1993.

WESTROPP, T. J. Brasil and the legendary islands of the north atlantic. Their history and fable. A contribution to the "Atlantis" problem. Proceedings ot the royal Irish academy. Dublin, vol. 30, n. 8, 1912.

ZIMMER, H. Keltische Beiträge II. Brendans Meerfahrt. Zeitschrift für Deutsches Alterthum. Leipzig: vol. XXXIII, p. 129-220, 1889. 